\title{
HUBUNGAN GAYA KEPEMIMPINAN KEPALA SEKOLAH DENGAN EFEKTIVITAS SEKOLAH MENENGAH ATAS NEGERI SE-KOTA PALANGKA RAYA
}

\author{
SUNIATI \\ Dosen Fakultas Keguruan dan Ilmu Pendidikan Universitas Muhammadiyah Palangkaraya
}

\begin{abstract}
This research was conducted at State Senior High Schools in Palangka Raya, Central Kalimantan, the purpose of this research is to know whether there is any significant relationship between Headmasters' Leadership Style toward the school effectiveness at State Senior high Schools in Palangka Raya simultaneously. This research was designed by using the correlation quantitative approach through survey method. Target population are all teachers at State Senior High Schools in Palangka Raya, which amount 163 teachers. The total number of research sample was 115 teachers. Sample was taken by using randomized proportional sampling technique. The result of this research conclude that there was a significant relationship between Headmasters' Leadership Style with the School Effectiveness, represented by the linear regression $\hat{Y}=a+b X=23,21+0,77 X$ and correlation coefficient $r_{y}=0.963$ which is significant at $\alpha=0,05$. This result of this study is expected to be useful for improving the school effectiveness in achieving its vision and mission of the objective of effective and efficient school. The director behaviour leadership of school can empower the teachers to implement the process of learning a good, soft, and production, and management to implement the appropriate principles of leadership with the level of maturity of teachers and others school employees.
\end{abstract}

Keywods: leadership style, school effectiveness.

\section{ABSTRAK}

Penelitian ini dilaksanakan di SMA Negeri se-Kota Palangka Raya, Kalimantan Tengah yang bertujuan untuk mengetahui apakah ada hubungan yang signifikan antara Gaya Kepemimpinan Kepala Sekolah terhadap efektivitas sekolah di SMA Negeri se-Kota Palangka Raya secara simultan. Penelitian ini dirancang dengan menggunakan pendekatan kuantitatif korelasional melalui metode survei. Populasi target adalah semua guru di SMA Negeri se-Kota Palangka Raya yang berjumlah 163 guru. Jumlah sampel penelitian adalah 115 guru. Sampel diambil dengan menggunakan teknik proporsional random sampling. Hasil penelitian ini menyimpulkan bahwa ada hubungan yang signifikan antara Gaya Kepemimpinan Kepala Sekolah dengan Efektivitas Sekolah, dengan persamaan regresi $\hat{Y}=a+b X=23,21+0,77 X$ dan koefisien korelasi $r_{y}=0,963$ yang signifikan pada $\alpha=0,05$. Hasil penelitian ini diharapkan dapat bermanfaat untuk meningkatkan efektivitas sekolah dalam mencapai visi dan misi tujuan sekolah yang efektif dan efisien. Perilaku kepemimpinan sekolah dapat mampu memberdayakan para guru untuk melaksanakan proses pembelajaran yang baik, lancar, dan produktif, serta berhasil menerapkan prinsip-prinsip kepemimpinan yang sesuai dengan tingkat kedewasaan guru dan pegawai lain di sekolah.

Kata kunci: gaya kepemimpinan, efektivitas sekolah

\section{PENDAHULUAN}

Penyelenggaraan sekolah yang efektif merupakan tangggung jawab bersama antara Pemerintah, Pemerintah Daerah, dan masyarakat sebagai amanat desentralisasi pendidikan sebagaimana termuat dalam Undang-Undang
Nomor 22 Tahun 1999 tentang Pemerintah Daerah yang menyebutkan bahwa "Pendidikan dan Kebudayaan telah ditetapkan sebagai salah satu bidang pemerintahan yang wajib dilaksanakan oleh Pemerintah Kabupaten/Kota". Perkembangan desentralisasi pendidikan ini 
akhirnya diperkuat pula dalam UU Nomor 32 Tahun 2004 tentang Pemerintah Daerah. Meskipun dalam penyelenggaraan pendidikan terjadi pembagian tugas dan kewenangan antara Pemerintah Pusat dan Pemerintah Daerah, namun kebijakan dalam bentuk standarisasi mutu, pedoman dan prosedur, serta kriteria pengelolaan pendidikan tetap menjadi tanggung jawab Menteri Pendidikan Nasional sebagaimana ditetapkan dalam Peraturan Pemerintah Nomor 19 tahun 2005 tentang Standar Nasional Pendidikan.

Selama ini sistem pendidikan dikembangkan oleh para eksekutif birokrasi dengan sistem yang monolitik sehingga kurang melibatkan pemikiran dan aspirasi para pendidik dan tenaga kependidikan maupun tuntutan kebutuhan masyarakat. Kepala sekolah dan Guru yang selama ini difungsikan sebagai palaksana, perlu diikutsertakan sebagai pengambil prakarsa, inisiatif dalam pengembangan sekolah. Begitupun para siswa, tidak boleh dipandang sebagai obyek didik yang tidak boleh berbeda pendapat dengan pendapat guru. Unsur manusia dalam pendidikan perlu ditempatkan sebagai manusia yang utuh dan mampu membentuk diri, serta bukan manusia yang dibentuk. Cita-cita membangun sistem pendidikan yang menjamin kebesaran bangsa, menempatkan keragaman budaya dan keunggulan lokal sebagai kekuatan bangsa dalam bersaing dan bersanding dengan negara lain perlu dimaknai strategi implementasinya sehingga dapat menciptakan sumber daya manusia yang berkualitas.

Pentingnya pemahaman terhadap keefektifan sekolah tidak saja dalam kaitan dengan meningkatkan mutu pendidikan tetapi juga sesuai dengan kebijakan nasional yaitu desentralisasi pendidikan dalam rangka pelaksanaan otonomi daerah. Berkenaan dengan desentralisasi pendidikan tersebut, di bidang pendidikan dasar dan menengah, Depdiknas telah menyiapkan konsep otonomi sekolah yaitu manajemen berbasis sekolah. Dengan konsep ini, pemerintah tidak hanya berharap pada meningkatnya mutu pendidikan melainkan juga tercapainya pemerataan, relevansi, dan efisiensi penyelenggaraan pendidikan.

Agar desentralisasi dan otonomi pendidikan berhasil dengan baik, kepemimpinan kepala sekolah perlu diberdayakan. Pemberdayaan berarti peningkatan kemampuan secara fungsional, sehingga kepala sekolah mampu berperan sesuai dengan tugas, wewenang, dan tanggung jawabnya. Kepala sekolah harus bertindak sebagai manajer dan pemimpin yang efektif. Sebagai manajer ia harus mampu mengatur agar semua potensi sekolah dapat berfungsi secara optimal. Hal ini dapat dilakukan jika kepala sekolah mampu melakukan fungsifungsi manajemen dengan baik, meliputi (1) perencanaan; (2) pengorganisasian;

pengarahan; dan (4) pengawasan. Kepala sekolah tidak perlu lagi ragu - ragu mengambil inisiatif dalam memimpin sekolahnya.

Keberhasilan suatu sekolah pada hakikatnya terletak pada efisiensi dan efektivitas penampilan seorang kepala sekolah. Sedangkan Sekolah sebagai lembaga pendidikan bertugas menyelenggarakan proses pendidikan dan proses belajar mengajar dalam usaha untuk mencerdaskan kehidupan bangsa. Dalam hal ini kepala sekolah sebagai seseorang yang diberi tugas untuk memimpin sekolah, kepala sekolah 
bertanggung jawab atas tercapainya tujuan sekolah. Kepala sekolah diharapkan menjadi pemimpin dan inovator di sekolah. Oleh sebab itu, kualitas kepemimpinan kepala sekolah adalah signifikan bagi keberhasilan sekolah.

Kepemimpinan adalah cara seseorang pemimpin mempengaruhi perilaku bawahan agar mau bekerja sama dan bekerja secara produktif untuk mencapai tujuan organisasi. Kepemimpinan yang dimaksud adalah kemampuan kepala sekolah dalam membina dan membimbing guru untuk melaksanakan kegiatan belajar mengajar (KBM) terutama kegiatan merencanakan, melaksanakan proses pembelajaran, serta menilai dan mengevaluasi hasil pembelajaran mengarah pada tercapainya kompetensi dasar yang harus dikuasai siswa terkait dengan pengetahuan, keterampilan dan sikap serta nilai yang direfleksikan dalam kebiasaan berfikir dan bertindak setelah mengikuti kegiatan pembelajaran.

Gaya kepemimpinan adalah sikap, gerakgerik atau lagak yang dipilih oleh seseorang pemimpin dalam menjalankan tugas kepemimpinannya. Gaya yang dipakai oleh seorang pemimpin satu dengan yang lain berlainan tergantung situasi dan kondisi kepemimpinannya. Gaya kepemimpinan merupakan norma perilaku yang dipergunakan seseorang pada saat orang tersebut mencoba mempengaruhi perilaku orang lain. Gaya kepemimpinan adalah suatu pola perilaku yang konsisten yang ditunjukan oleh pemimpin dan diketahui pihak lain ketika pemimpin berusaha mempengaruhi kegiatan-kegiatan orang lain.
Gaya kepemimpinan yang kurang melibatkan bawahan dalam mengambil keputusan maka akan mengakibatkan adanya disharmonisasi hubungan antara pemimpin dan yang dipimpin. Kepemimpinan yang baik tentunya sangat berdampak pada tercapai tidaknya tujuan organisasi karena pemimpin memiliki pengaruh terhadap kinerja yang dipimpinnya. Kemampuan untuk mempengaruhi suatu kelompok untuk mencapai tujuan merupakan bagian dari kepemimpinan. Konsep kepemimpinan erat sekali hubungannya dengan konsep kekuasaan. Dengan kekuasaan pemimpin memperoleh alat untuk mempengaruhi perilaku para pengikutnya. Terdapat beberapa sumber dan bentuk kekuasaan, yaitu kekuasaan paksaan, legitimasi, keahlian, penghargaan, referensi, informasi, dan hubungan.

Perbandingan jumlah guru dan siswa yang ada di wilayah Kalimantan Tengah pada tahun 2009 untuk masing-masing jenjang pendidikan, menunjukkan jumlah tenaga pendidik masih sangat kurang bila dibandingkan dengan jumlah peserta didiknya. Untuk jenjang pendidikan $\mathrm{SD} / \mathrm{MI}$, rasio guru dan murid se Kalimantan Tengah adalah 1:65. Artinya bila dirata-rata satu orang guru mengajar enam puluh lima orang murid. Tak jauh berbeda dengan jenjang SMP/ MTs, rasio guru dan pelajar se Kalteng yakni, 1:55. Artinya bila dirata-rata satu orang guru mengajar lima puluh lima orang pelajar. Rasio yang paling besar terdapat pada jenjang SMA/SMK/MAN se Kalimantan Tengah yaitu, 1:88. Artinya bila dirata-rata satu orang guru mengajar delapan puluh delapan siswa. Berdasarkan data terakhir yang diperoleh Disdik Kalteng, jumlah guru di kabupaten/kota se 
Kalimantan Tengah adalah 39.146 orang. Tiga wilayah yang memiliki jumlah tenaga pengajar terbanyak antara lain; Kabupaten Kapuas dengan jumlah guru sebanyak 6.350 orang, kemudian Kota Palangka Raya sejumlah 4.661 orang. Diurutan ketiga adalah Kabupaten Kotawaringin Timur (Kotim) dengan jumlah 4.600 orang guru. Menurut Slamet, kendala yang dihadapi selama ini adalah masalah penyebaran atau pengaturan penempatan guru yang kurang merata serta pendataan yang kurang akurat. Terkadang terdapat kondisi pada suatu kabupaten yang kekurangan guru, tetapi ada kabupaten lain yang memiliki kelebihan guru. Kondisi tersebut disebabkan setiap kabupaten/kota memiliki otoritas masing-masing untuk mengangkat guru honorer dan mengajukan formasi tenaga pengajar di daerahnya masing-masing.

Berdasarkan uraian tersebut di atas, maka penelitian ini akan berusaha mengkaji " Hubungan Gaya Kepemimpinan Kepala Sekolah dengan Efektivitas Sekolah Menengah Atas Negeri seKota Palangkaraya".

\section{METODOLOGI}

Metode penelitian yang digunakan dalam penelitian ini adalah metode survey. Penelitian ini bersifat korelasional karena penelitian berusaha menyelidiki hubungan antara beberapa variabel penelitian yaitu variabel manajemen berbasis sekolah dan gaya kepemimpinan kepala sekolah sebagai variabel prediktor dan efektivitas sekolah sebagai variabel kriterion. Studi korelasi ini akan menggunakan analisis korelasi dan regresi.

Populasi target dalam penelitian ini adalah guru - guru di SMA di Kota Palangkaraya di bawah naungan Dinas Pendidikan Kota
Palangkaraya, berjumlah 163 orang yang tersebar pada 5 (lima) SMA Negeri.

Pengambilan sampel dengan teknik proporsional random sampling karena semua sampel mempunyai hak yang sama, yaitu pengambilan sampel yang didasarkan unit sekolah secara proporsional atau seimbang dan pengambilannya dilakukan secara random (tidak dipilih namun melalui undian) sehingga di dapat jumlah sampel sebanyak 115 orang guru.

Dalam penelitian ini terdapat dua data yang akan dikumpulkan, yaitu data gaya kepemimpinan kepala sekolah, dan data efektivitas sekolah. Teknik pengumpulan data tentang efektivitas sekolah dan gaya kepemimpinan kepala sekolah menggunakan metode kuesioner dengan Skala Likert. Selanjutnya kuesioner diujikan kepada para guru.

Dalam penelitian ini menggunakan kuesioner sebagai alat pengumpul data, yaitu lembar kuesioner variabel efektivitas sekolah, dan variabel gaya kepemimpinan kepala sekolah. Teknik pengumpulan data yang digunakan adalah data primer.

Analisis data dilakukan melalui tiga tahapan, yaitu tahap deskripsi data, tahap uji persyaratan analisis, dan tahap pengujian hipotesis.

\section{HASIL DAN PEMBAHASAN}

Deskripsi data yang akan disajikan dari hasil penelitian ini adalah untuk memberikan gambaran secara umum mengenai penyebaran data yang diperoleh dilapangan. Data yang disajikan berupa data mentah yang diolah menggunakan teknik statistik deskripsi. Adapun dalam deskripsi data ini yang disajikan dengan 
bentuk distribusi frekuensi, total skor, harga skor rata-rata, simpangan baku, modus, median, skor maksimum dan skor minimum yang disertai histogram. Deskripsi tersebut berguna untuk menjelaskan penyebaran data menurut frekwensinya, untuk menjelaskan kecenderungan terbanyak, untuk menjelaskan kecenderugan tengah, untuk menjelaskan pola penyebaran (maksimum-minimum), untuk menjelaskan pola penyebaran atau homogenitas data. Data tentang efektivitas sekolah dan gaya kepemimpinan kepala sekolah diperoleh melalui kuesioner. Sampel yang diambil data dalam penelitian ini adalah 115 orang guru SMA Negeri se-Kota Palangka Raya.

Mengenai data dari hasil penelitian variabel terikat yaitu Efektivitas sekolah $(\mathrm{Y})$ yang dijaring melalui penyebaran kuesioner, dengan jumlah pertanyaan sebanyak 33 butir instrumen dengan penggunaan skala pilihan jawaban skala lima (5 opsion), mempunyai skor teoretik antara 33 sampai 165 . Sedangkan skor empirik menyebar dari skor terendah 95 sampai dengan skor tertinggi 166, dengan skor total yaitu 16184, rata rata (M) 140,73, simpangan baku (SD) 11,081, modus (Mo) 144 median (Me) 143,00 dan varians 122,778 .

Mengenai data dari hasil penelitian variabel bebas yaitu Gaya Kepemimpinan Kepala Sekolah (X) yang dijaring melalui penyebaran kuesioner, dengan jumlah pertanyaan sebanyak 37 butir instrumen dengan penggunaan skala pilihan jawaban skala lima (5 opsion), mempunyai skor teoretik antara 37 sampai 175 . Sedangkan skor empirik menyebar dari skor terendah 112 sampai dengan skor tertinggi 175, dengan skor total yaitu 17553, rata rata (M) 152,63, simpangan baku
(SD) 13,857, modus (Mo) 145, median (Me) 154,00 dan varians 192,006.

Uji normalitas distribusi frekuensi dari variabel $X$ dan $Y$ dilakukan dengan uji Lilliefors. Sesuai dengan ketentuannya, kriteria normalitas menurut uji Lilliefors adalah apabila nilai tertinggi dari $L_{\text {hitung }} \leq$ nilai Ltabel maka data berdistribusi normal.

Hasil perhitungan uji normalitas terhadap semua data dari masing-masing variabel pada taraf signifikansi 0,05 diperoleh hasil seperti tersaji pada tabel 1. berikut:

Berdasarkan tabel 1 dapat disimpulkan bahwa distribusi data variabel $X$ dan $Y$ berdistribusi normal, sehingga memenuhi persyaratan pengujian regresi dan korelasi.

\section{Uji Homogenitas Galat Taksiran Regresi $\mathrm{Y}$ atas $\mathrm{X}$}

Berdasarkan hasil perhitungan pengujian homogenitas tersebut seperti yang dijelasskan di atas diperoleh nilai $X_{\text {hitung }}^{2}=1,7541$ dengan $n=$ 115 dan taraf signifikan $\alpha=0,05$ diperoleh $X_{\text {tabel }}^{2}=$ 40,1 . Oleh karena $x_{\text {hitung }}^{2}<x^{2}$ tabel, atau $1,7541<$ 40,1 dengan demikian maka semua data variabel efektivitas sekolah atas variabel implemntasi manajemen berbasis sekolah adalah homogen.

Hipotesis dalam penelitian ini berbunyi terdapat hubungan positif antara Gaya Kepemimpinan Kepala Sekolah dengan Efektivitas sekolah. Untuk pengujian hipotesis dengan menggunakan analisis regresi dan korelasi sederhana terhadap dua variabel Gaya Kepemimpinan Kepala Sekolah atas Efektivitas sekolah menghasilkan arah regresi $b$ sebesar 0,77 dan konstanta atau a sebesar 23,21. Maka dapat digambarkan bentuk hubungan antara kedua variabel tersebut oleh persaman regresi 
$\hat{Y}=a+b X=23,21+0,77 X$. Selanjutnya untuk mengetahui derajat keberartian dilakukan Uji $F$, yang hasilnya dapat dirangkum pada tabel 2.

Dari nilai yang tertera pada tabel ANAVA di atas untuk uji regresi sederhana diperoleh $\mathrm{F}_{\text {hitung }}=$ 12,773 untuk $\mathrm{db}$ pembilang adalah 1 dan $\mathrm{db}$ penyebut 113 , memiliki nilai yang lebih besar dari $F_{\text {tabel }}=3,49$ sedangkan untuk taraf signifikansi $1 \%$ diperoleh $F_{\text {tabel }}=6,90$. Dengan demikian dari kondisi ini dapat disimpulkan bahwa koefisien arah dari regresi adalah signifikan atau sangat berarti.

Berdasarkan pada tabel ANAVA di atas untuk uji linieritas diperoleh nilai $F_{\text {hitung }}=-0,896$ untuk taraf nyata $5 \%$, diperoleh $F_{\text {tabel }}=1,60$ dan selanjutnya untuk taraf nyata $1 \%$ diperoleh $\mathrm{F}_{\text {tabel }}=$ 1,94, untuk db pembilang 15 dan penyebut 98 .

Berpedoman pada nilai - nilai tersebut dapat disimpulkan bahwa regresi adalah berpola linier. Selanjutnya dari pengujian tersebut untuk persamaan regresi $\hat{Y}=a+b X=23,21+0,77 X$, dapat dipertanggung jawabkan untuk dijadikan alat dalam pengambilan keputusan.

Model hubungan antara variabel Gaya kepemimpinan Kepala Sekolah (X) dengan Efektivitas sekolah $(Y)$ dengan menggunakan model persamaan regresi $\hat{Y}=a+b X=23,21+$ $0,77 X$, dapat dilihat pada grafik 1 .

Persamaan regresi $\hat{Y}=a+b X=23,21+$ $0,77 X$ tersebut dapat untuk menjelaskan ramalan (forecasting). Dengan hasil pengujian tersebut, maka dinyatakan bahwa persamaan regresi $\hat{Y}=a$ $+b X=23,21+0,77 X$ sangat signifikan dan linier, artinya setiap peningkatan satu skor gaya kepemimpinan kepala sekolah $(X)$ akan diikuti oleh kenaikan efektivitas sekolah $(\mathrm{Y})$ sebesar 0,77 dan pada konstanta 23,21. Tingkat keeratan hubungan antara gaya kepemimpinan kepala sekolah (X) dengan Efektivitas sekolah ( $Y$ ) ditunjukkan oleh Koefisien Korelasi $\left(r_{y}\right)$ sebesar 0,963 .

Selanjutnya dilakukan uji signifikansi menggunakan uji-t yang hasilnya dapat dilihat pada tabel 3 .

Berdasarkan tabel 3 tersebut dapat diketahui bahwa koefisien korelasi sangat signifikan. Hal ini karena $t$ hitung 38,026 > daripada $t$ tabel 1,66 pada $\alpha=0,05$ dengan $\mathrm{db}=$ 113. Maka dapat dikatakan bahwa hubungan antara Gaya Kepemimpinan Kepala Sekolah (X) dengan Efektivitas sekolah $(\mathrm{Y})$ sangat signifikan. Temuan ini menyimpulan bahwa terdapat hubungan yang positif antara gaya kepemimpinan kepala sekolah dengan Efektivitas sekolah. Berarti makin baik kepemimpinan yang ditunjukkan oleh kepala sekolah dengan meningkatnya mutu pendidikan melalui komunikasi interpersonal, keteladanan, membagi tugas, membagi informasi dan mengambil keputusan yang berkaitan dengan upaya mewujudkan visi, tujuan dan sasaran sekolah agar tercapai kualitas efektivitas sekolah/unggul.

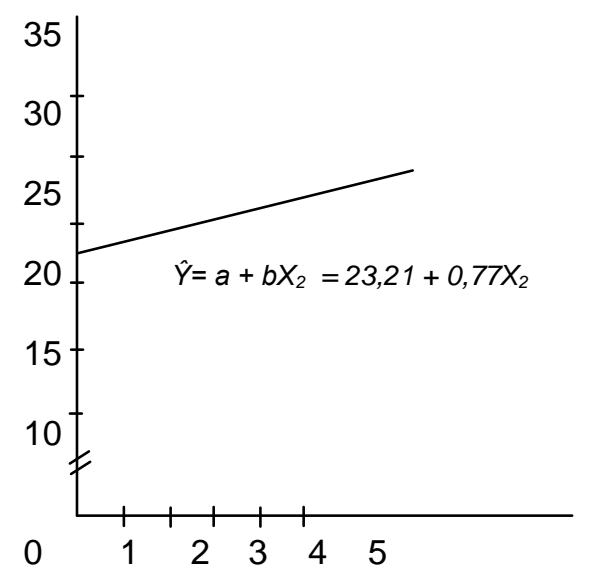

Grafik 1. Garis Regresi Hubungan Antara Gaya Kepemimpinan Kepala Sekolah (X) dengan Efektivitas sekolah $(\mathrm{Y})$ 


\section{Saran}

Berdasarkan hasil penelitian dan kesimpulan, maka disarankan sebagai berikut:

1. Dalam rangka meningkatkan mutu pendidikan dengan pengelolaan sekolah secara efektif dan dan efisien serta sejalan dengan pelaksanaan desentralisasi pendidikan, para penyelenggara pendidikan baik di pusat, di daerah, maupun di sekolah perlu memperhatikan berbagai aspek yang berkenaan dengan input sekolah, kepuasan kerja guru, partisipasi orang tua siswa, dan iklim sekolah.

2. Sekolah harus banyak berkomunikasi, berinteraksi dengan masyarakat, melalui instansi resmi maupun tidak resmi, sehingga kebutuhan masyarakat dapat dipenuhi dan dapat memberi kesadaran tentang pentingnya meningkatkan kualitas pendidikan.

3. Kepada kepala sekolah disarankan untuk memiliki pengetahuan kepemimpinan, perencanaan dan pandangan yang luas tentang sekolah dan pendidikan, melakukan fungsinya sebagai manajer sekolah dalam meningkatkan proses belajar mengajar, serta melakukan tukar pikiran dan studi banding antar sekolah untuk menyerap kiat-kiat kepemimpinan dari kepala sekolah yang lain.

4. Kepala Sekolah harus dapat bekerja dalam team agar mencapai hasil yang optimal. Dalam hal ini mempengaruhi semua personil sekolah melalui komunikasi interpersonal, keteladanan, membagi tugas, membagi informasi dan mengambil keputusan yang berkaitan dengan upaya mewujudkan visi, tujuan dan sasaran sekolah agar tercapai kualitas efektivitas sekolah/unggul.

\section{DAFTAR PUSTAKA}

Al-Qur'an terjemahan. Bandung: PT. Syaamil Cipta Media.

Anwar, Moch. Idhochi. 2003. Administrasi Pendidikan dan Manajemen Biaya Pendidikan. Bandung : CV. Alfabeta.

Danim, Sudarwan. 2003. Menjadi Komunitas Pembelajar; Kepemimpinan Transformasional dalam Komunitas Organisasi Pembelajaran. Jakarta: PT. Bumi Aksara.

. 2008. Kinerja Staf dan Organisasi, Bandung: Pustaka Setia.

Dewanto \& Tarsis Tarmudji. 1995. Metode Statistika. Yogyakarta: Liberty.

Ghozali, Abbas. Tinjauan Literatur : Effective School Research, Jurnal Pendidikan dan Kebudayaan, No. 021. Tahun ke-5, Januari 2000, Balitbang Depdiknas.

Gibson, Ivancevich, Donnelly. 1996. Organisasi, Perilaku, Struktur, Proses, (Alih Bahasa Nunuk Adiarni), Jakarta: Penerbit Binarupa Aksara.

1999. Manajemen. edisi kedua. Yogyakarta: BPFE

Hall, John, et.al. 2002. Transformational Leadership: The Transformation of Managers and Associates. on line : www.edis.ifas.ufl.edu di akses pada minggu tanggal 4 April 2010

Hasibuan, Malayu. 2003. Organisasi dan Motivasi: Dasar Peningkatan Produktivitas. Jakarta: Bumi Aksara.

Harefa, Andrias. Kepemimpinan-Manajemen: Visionaris. [Online]. http://www.pembelajar.com/pemimpin/p eminari.htm di akses pada tanggal minggu 4 April 2010

Heidjrachman, H. Suad. 2002. Manajemen Personalia. Yogyakarta : BPFE 
Komariah, Aan dan Triatna, Cepi. 2008. Visionary Leadership menuju Sekolah Efektif. Bandung: Rosdakarya.

Koster, Wayan.2001, Analisis Komparatif Antara Efektivitas sekolah dengan Sekolah Tidak Efektif, www.depdiknas.go.id/jurnal/12.htm Jum'at, 9 April 2010

Law, Sue \& Glover, Derek. 2000. Educational Leadership and Learning; practice, policy and research. Buckingham: Open university Press.

Madhi, Jamal. 2001. Menjadi Pemimpin yang Efektif dan Berpengaruh Tinjauan Manajemen Kepemimpinan Islam. Bandung. PT Syamil Cipta Media.

Moeljono, Djokosantoso. 2009. More About Beyond Leadership; dua belas konsep kepemimpinan. Jakarta: PT. Elex Media Komputindo.

Nawawi, Hadari. 1989. Organisasi sekolah dan pengelolaan kelas sebagai lembaga pendidikan. CV. Haji Masagung. Jakarta.

Nawawi, Hadari dan Hadari, M. Martini. 2006. Kepemimpinan yang Efektif. Yogyakarta: Gajah Mada University Press.

Nurgiyantoro, Burhan., dkk. 2004. Statistika Terapan untuk Penelitian IImu - IImu Sosial. Yogyakarta: Gajah Mada University Press.

Rahman, dkk. 2006. Peran Strategis Kapala Sekolah dalam Meningkatkan Mutu Pendidikan. Jatinangor: Alqaprint.

Rahman, Samson. 2006. Sukses Menjadi Pemimpin Islami. Jakarta: Maghfirah Pustaka.

Ramdhan, Muhammad. 2005. "Memimpin Sesuai Keadaan". Makalah, Jakarta

Rivai, Veithzal dan Mulyadi, Deddy. 2009. Kepemimpinan dan Perilaku Organisasi, edisi ke tiga. Jakarta: PT. Rajagrafindo Persada.
Robbins, Stephen P. 2003. Organizational Behavior. New Jersey: Pearson Education International.

Scheerens, Jaap. 2003. Menjadikan Efektivitas sekolah. Jakarta: Logos.

Sastrodiningrat, Soebagio. 2002. Manajemen dan Kepemimpinan. Jakarta. IHC.

Siagian, Sondang P. 2002. Kiat meningkatkan Produktivitas kerja. Jakarta: Rineka Cipta.

Sugiyono.2009. Metode Penelitian Pendidikan: Pedekatan Kuantitatif, Kualitatif,danR\&D.Bandung: Alfabeta

Toha, Miftah.1990. Kepemimpinan Dalam Manajemen, Jakarta : Rajawali Pers, cet. Ke-4,

Wahab, Abdul Azis. 2008. Anatomi Organisasi dan Kepemimpinan Pendidikan (Telaah terhadap Organisasi dan Pengelolaan Organiosasi Pendidikan). Bandung: Alfabeta.

Wahjosumidjo. 2003. Kepemimpinan Kepala Sekolah, Tinjauan Teoritik dan Permasalahannya. Jakarta: PT Raja Grafindo Persada.

Yukl, Gery. 2005. Kepemimpinan dalam Organisasi, edisi bahasa Indonesia. Jakarta: PT. Indeks kelompok Gramedia. 